\title{
Is subdural hemorrhage after pulmonary endarterectomy underrecognized?
}

Jonathan Yap, MBBS, MRCP, MPH, ${ }^{\mathrm{a}}$ Wen Ruan, MBBS, MRCP, ${ }^{\mathrm{a}}$ Alicia Chia, MBBS, MRCS, ${ }^{\mathrm{b}}$ Kenny Loh, MBBS, M Med, ${ }^{\mathrm{c}}$ Foong Koon Cheah, MBChB, MRCP, FRCR, ${ }^{\mathrm{d}}$ Ai Leen Ang, MBBS, MRCP, Ghee Chee Phua, MBBS, MRCP, ${ }^{\mathrm{f}}$ Duu Wen Sewa, MBBS, MRCP, ${ }^{\mathrm{f}}$ David Jenkins, MBBS, FRCS, ${ }^{\mathrm{g}}$ Ju Le Tan, MBBS, MRCP, ${ }^{\mathrm{a}}$ Victor Chao, MBBS, FRCS, ${ }^{\mathrm{b}}$ and Soo Teik Lim, MBBS, FRCP, ${ }^{\mathrm{a}}$ Singapore, and Cambridge, United Kingdom

\footnotetext{
From the Departments of ${ }^{\mathrm{a} C}$ ardiology and ${ }^{\mathrm{b}}$ Cardiothoracic Surgery, National Heart Centre Singapore, Singapore Departments of ${ }^{\mathrm{c}}$ Anesthesiology, ${ }^{\mathrm{d}}$ Diagnostic Radiology, ${ }^{\mathrm{e}}$ Hematology, and ${ }^{\mathrm{f}}$ Respiratory Medicine, Singapore General Hospital, Singapore; and ${ }^{g}$ Department of Cardiothoracic Surgery, Royal Papworth Hospital, Cambridge, United Kingdom.

Drs Yap and Ruan contributed equally to this article.

Disclosures: Authors have nothing to disclose with regard to commercial support.

Received for publication Jan 30, 2018; revisions received May 31, 2018; accepted for publication June 5, 2018; available ahead of print July 26, 2018.

Address for reprints: Jonathan Yap, MBBS, MRCP, MPH, National Heart Centre Singapore, 5 Hospital Dr, Singapore 169609 (E-mail: jonyap@yahoo.com).

J Thorac Cardiovasc Surg 2018;156:2039-42

$0022-5223 / \$ 36.00$

Copyright () 2018 by The American Association for Thoracic Surgery

https://doi.org/10.1016/j.jtcvs.2018.06.029
}

Video clip is available online.

Pulmonary endarterectomy (PEA) is part of the treatment options for suitable patients with chronic thromboembolic pulmonary hypertension (CTEPH), ${ }^{1}$ affording improved quality of life and survival. Subdural hemorrhage (SDH) is a potential complication of PEA and may result from a combination of factors, including the use of anticoagulation therapy, deep hypothermic circulatory arrest, intracranial fluid shifts, and changes in perfusion. However, the incidence of SDH has previously not been commonly reported. In one series of patients undergoing PEA in chronic thromboembolic disease (CTED), an incidence of $14 \%$ was reported. ${ }^{2}$ In the present study, we examined the incidence and management of CTEPH patients with SDH post-PEA (Video 1).

\section{METHODS}

This is a retrospective case series of consecutive CTEPH patients who underwent PEA between November 2016 and August 2017 from an Asian tertiary pulmonary hypertension center. Our multidisciplinary team received training at 2 expert PEA centers (San Diego and Papworth, UK), and all the procedures were proctored by a senior surgeon from Papworth. All patients were managed perioperatively in accordance with published Western protocols, ${ }^{3-6}$ with anticoagulation stopped before surgery and subcutaneous enoxaparin started at 24 hours post-PEA if no contraindications exist. Initially, patients with neurologic signs and symptoms were scheduled for a noncontrast brain computed tomography (CT) scan. Subsequently, all patients post-PEA were routinely scanned in

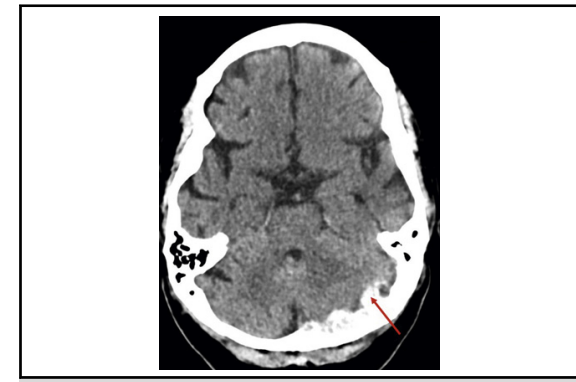

Computed tomography scan of the brain showing an acute hyperintense subdural hemorrhage (red arrow) after pulmonary endarterectomy.

\section{Central Message}

A high incidence of subdural hemorrhage was noted in our series of patients with chronic thromboembolic pulmonary hypertension post-pulmonary endarterectomy, which may have been underrecognized. The significance and management of this complication is discussed.

See Editorial Commentary page 2043

view of the higher incidence of SDH noted. This study was approved by the institutional Ethics Review Board (Singhealth CIRB 2017/2388).

\section{RESULTS}

A total of 10 patients ( 8 females; mean age, 56.7 years [range, 45-64 years], mean pulmonary artery pressure $48.5 \mathrm{~mm} \mathrm{Hg}$ [range, 37-67 mm Hg]) underwent PEA. Mean cardiopulmonary bypass, cross-clamp, and deep hypothermic circulatory arrest times were $305 \pm 44$ minutes, $84 \pm 29$ minutes, and $46 \pm 15$ minutes, respectively.

Seven of the 10 patients underwent brain CT scan postprocedure ( 2 with headache, 1 with delirium, 1 with an accidental fall, and 3 asymptomatic). The remaining 3 patients were not scanned as they were part of the earlier cohort and were asymptomatic. Six patients had SDH (2 headache, 1 delirium, 1 accidental fall, 2 asymptomatic). One symptomatic patient with headache had a mild midline shift and required a frontal burr hole and suboccipital craniectomy for evacuation of SDH on postoperative day 4 . 


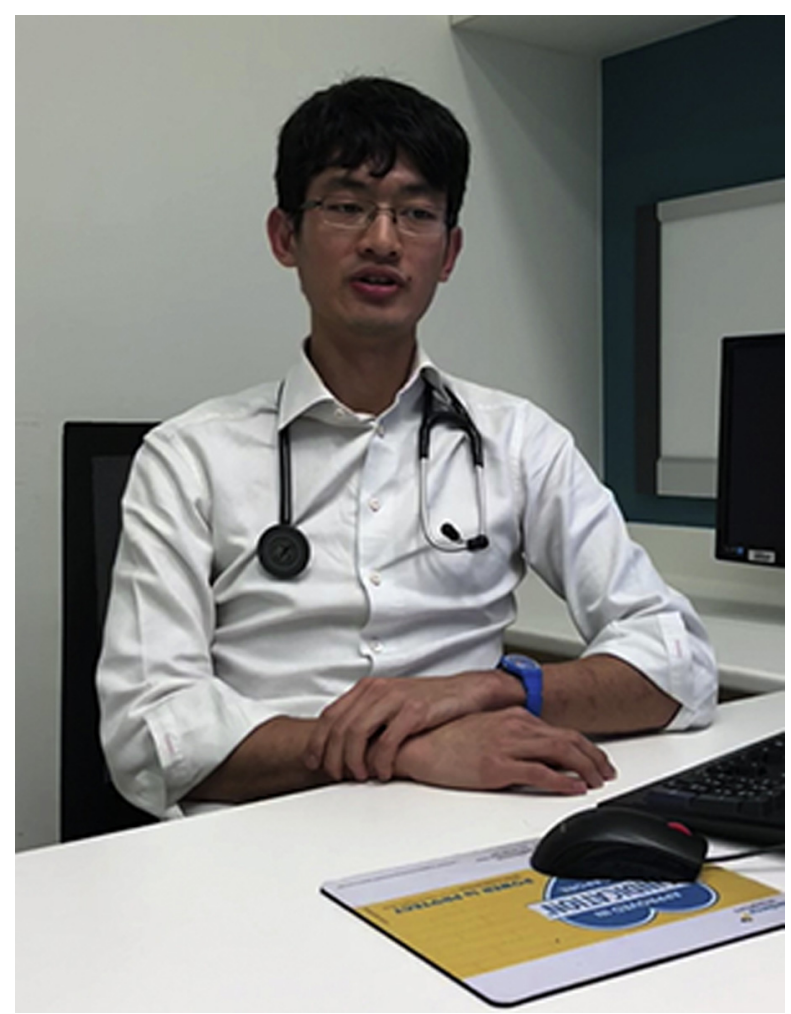

VIDEO 1. Subdural hemorrhage after pulmonary endarterectomy: importance and relevance. Video available at: https://www.jtcvs.org/ article/S0022-5223(18)31763-X/fulltext.

The remaining patients had a small SDH that were managed conservatively with reversal and cessation of anticoagulation. Anticoagulation was resumed at varying times (range, 11 days to 9 weeks postoperatively) after stability on repeat brain $\mathrm{CT}$ and on consult with the neurosurgical team. No thrombotic events (eg, stroke, pulmonary embolism, deep vein thrombosis) were noted during the period when anticoagulation was stopped (Table 1).

At follow-up (range, 4 months to 1 year), there was a significant reduction in pulmonary pressures for all patients and no mortalities. No neurologic deficits were noted.

\section{DISCUSSION}

In our case series, the overall incidence of SDH was $60 \%$ (noting that the first 3 patients in our series were asymptomatic and not routinely scanned). Although SDH is a known complication, the data on its incidence is sparse. A large international registry from Europe and

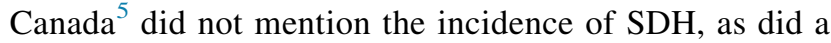
large cohort from United States. ${ }^{6,7}$ Studies from Asian countries like Japan and Taiwan, ${ }^{8,9}$ as well as a systematic review, ${ }^{10}$ also did not mention any cases of SDH. The Papworth group reported a $14 \%$ incidence of SDH (6 out of 42 patients) in its series of CTED patients undergoing PEA, all of whom had a small SDH requiring no intervention. ${ }^{2}$ They did not routinely screen all patients. Our higher incidence could be a result of routine screening for SDH postoperatively. In addition, CTED patients might not be comparable to CTEPH patients, with a potentially higher disease burden and worse hemodynamics in the latter. Excluding the 2 asymptomatic patients, the patient with an accidental fall, and the patient with delirium (likely due to postoperative stressors), the "revised" incidence of symptomatic SDH in our cohort would be $20 \%$, slightly higher than that reported by the Papworth group.

Several causes of SDH have been postulated. ${ }^{11-13} \mathrm{SDH}$ after cardiac and aortic surgeries have been reported. ${ }^{11,12}$ In a series of patients undergoing aortic surgery, $15 \%$ were found to have symptomatic SDH, all of which were managed conservatively. ${ }^{11}$ First, rapid fluid shifts may occur in the postoperative period as a result of postoperative diuresis (from the mannitol in the bypass solution and the mannitol and furosemide given postoperatively to maintain "dry lung," as well as the reduction in right ventricular afterload and improvement in cardiac output). Second, the deep hypothermic protocol with circulatory arrest and subsequent rewarming may cause marked perfusion changes in the brain, with the vasoconstrictive effect of hypothermia and subsequent vasodilating effect of rewarming. The foregoing factors may result in shearing of the bridging veins between the 2 meningeal layers, leading to SDH. ${ }^{11-13}$ In addition, Asians are known to be at a higher risk of intracranial hemorrhage compared with their Western counterparts. ${ }^{14}$ The routine early resumption of anticoagulation may contribute to this phenomenon.

The clinical significance of this high incidence of SDH is uncertain, and the question remains as to whether if these generally small SDHs would have any major clinical consequences (especially the 2 asymptomatic SDHs picked up on routine screening). Nevertheless, we describe our experience in effectively dealing with this issue. Apart from 1 patient who had a mild midline shift necessitating burr hole drainage and craniectomy, the remaining 5 patients with small SDH were treated effectively with reversal and cessation of anticoagulation. Anticoagulation was resumed on stability/improvement of the bleed on repeat CT brain. Interestingly, and fortuitously, although anticoagulation was stopped for a few weeks in several patients, no thrombotic events were noted.

A major limitation of this study is that preoperative brain CT scans were not performed to document the exact onset of SDH, and patients on chronic oral anticoagulation are known to be more susceptible to SDH. ${ }^{15}$ Nevertheless, the hyperintense appearance on CT indicates an acute onset, likely in the perioperative period. Standard protocols recommend early resumption of anticoagulation, usually on postoperative day 1 , as well as achievement of 
TABLE 1. Characteristics of patients with SDH after PEA

\begin{tabular}{|c|c|c|c|c|c|c|}
\hline Characteristic & Case 1 & Case 2 & Case 3 & Case 4 & Case 5 & Case 6 \\
\hline Age, $y$ & 45 & 67 & 55 & 61 & 52 & 57 \\
\hline Sex & Female & Female & Female & Female & Female & Male \\
\hline $\begin{array}{l}\text { Preoperative } \\
\text { anticoagulant }\end{array}$ & Warfarin & Warfarin & Warfarin & Warfarin & Rivaroxaban & Warfarin \\
\hline $\begin{array}{l}\text { Cardiopulmonary } \\
\text { bypass time, } \min \end{array}$ & 303 & 356 & 319 & 230 & 311 & 283 \\
\hline $\begin{array}{l}\text { Deep hypothermic } \\
\text { circulatory } \\
\text { arrest time, min }\end{array}$ & 47 & 58 & 54 & 14 & 42 & 36 \\
\hline $\begin{array}{l}\text { Initiation of } \\
\text { enoxaparin }\end{array}$ & $\begin{array}{l}\text { POD } 0 \text { (anti- } \\
\text { phospholipid } \\
\text { syndrome) }\end{array}$ & POD 1 & POD 1 & POD 1 & POD 1 & POD 1 \\
\hline Symptom & Headache & Headache & Delirium & Accidental fall & Asymptomatic & Asymptomatic \\
\hline $\mathrm{SDH}^{*}$ & Acute & Acute-on-chronic & Acute & Acute-on-chronic & Acute & Acute \\
\hline Location of SDH & $\begin{array}{c}\text { Bilateral frontal } \\
\text { and posterior } \\
\text { fossa }\end{array}$ & $\begin{array}{l}\text { Left frontoparietal } \\
\text { and occipitoparietal }\end{array}$ & $\begin{array}{c}\text { Left posterior } \\
\text { fossa }\end{array}$ & Left frontoparietal & $\begin{array}{l}\text { Left frontoparietal, } \\
\text { posterior falx and } \\
\text { right tentorial }\end{array}$ & $\begin{array}{c}\text { Right temporo- } \\
\text { occipital }\end{array}$ \\
\hline $\begin{array}{l}\text { Timing of } \\
\text { diagnosis }\end{array}$ & POD 4 & POD 8 & POD 8 & POD 5 & POD 7 & POD 6 \\
\hline Intervention & $\begin{array}{l}\text { Burr hole and } \\
\text { craniectomy }\end{array}$ & Conservative & Conservative & Conservative & Conservative & Conservative \\
\hline $\begin{array}{l}\text { Resumption of } \\
\text { anticoagulation }\end{array}$ & $\begin{array}{l}\text { Warfarin } \\
\text { resumed } \\
\text { at } 5 \mathrm{wk} \text { (repeat } \\
\mathrm{CT} \text { at } 8 \mathrm{wk} \\
\text { showed } \\
\text { complete } \\
\text { resolution) }\end{array}$ & $\begin{array}{l}\text { Warfarin } \\
\text { resumed } \\
\text { at } 9 \text { wk (repeat } \\
\text { CT at } 11 \text { wk } \\
\text { showed } \\
\text { complete } \\
\text { resolution) }\end{array}$ & $\begin{array}{l}\text { Warfarin } \\
\text { resumed } \\
\text { at } 3 \mathrm{wk} \\
\text { (repeat } \mathrm{CT} \\
\text { at } 6 \mathrm{wk} \\
\text { showed } \\
\text { complete } \\
\text { resolution) }\end{array}$ & $\begin{array}{c}\text { Warfarin } \\
\text { resumed } \\
\text { at } 3 \mathrm{wk} \text { (repeat } \\
\mathrm{CT} \text { at } 6 \mathrm{wk} \\
\text { showed complete } \\
\text { resolution) }\end{array}$ & $\begin{array}{l}\text { Dabigatran } \\
\text { resumed } \\
\text { on POD } 12 \\
\text { (repeat CT at } \\
8 \text { wk showed } \\
\text { complete } \\
\text { resolution) }\end{array}$ & $\begin{array}{l}\text { Dabigatran } \\
\text { resumed on } \\
\text { POD } 11 \\
\text { (repeat CT } \\
\text { at } 10 \mathrm{wk} \\
\text { showed } \\
\text { complete } \\
\text { resolution) }\end{array}$ \\
\hline $\begin{array}{l}\text { Net fluid balance } \\
\text { for first } 24 \mathrm{~h}, \mathrm{~mL}\end{array}$ & -1896 & -400 & -960 & -1000 & -1600 & -500 \\
\hline $\begin{array}{l}\text { Serum osmolality } \\
\text { on POD } 1, \mathrm{mmol} / \mathrm{kg}\end{array}$ & 325 & 324 & 320 & 318 & 318 & 325 \\
\hline $\begin{array}{l}\text { CVP, preoperative vs } \\
\text { POD } 0-1, \mathrm{~mm} \mathrm{Hg}^{\dagger}\end{array}$ & 22 vs 9 & 16 vs 10 & 8 vs 9 & 7 vs 8 & 14 vs 13 & 12 vs 10 \\
\hline $\begin{array}{l}\text { Mean PA pressure, } \\
\text { preoperative vs } \\
\text { POD } 0-1, \mathrm{~mm} \mathrm{Hg}^{\dagger}\end{array}$ & 54 vs 24 & 49 vs 37 & 67 vs 43 & 40 vs 35 & 42 vs 27 & 46 vs 26 \\
\hline $\begin{array}{l}\text { PVR, preoperative vs } \\
\text { POD } 0-1 \text {, Woods } \dagger\end{array}$ & 10.5 vs 3.2 & 11.8 vs 6.8 & 14 vs 6.6 & 14 vs 10.9 & 8.9 vs 4.6 & 10.4 vs 3.2 \\
\hline
\end{tabular}

$P O D$, Postoperative day; $S D H$, subdural hematoma; $C T$, computed tomography; $C V P$, central venous pressure; $P A$, pulmonary artery; $P V R$, pulmonary vascular resistance. * Preoperative, electively at a separate admission before the operation; POD 0-1, postoperative day 0 or 1 in the intensive care unit. $\dagger$ A hyperdense SDH on CT was defined as acute, and an isodense or hypodense SDH on CT was defined as chronic.

negative balance to avoid pulmonary edema; however, these protocols have been based mainly on Western cohorts. $^{2-5}$ Our team acknowledges that Asians may behave differently, and in light of our experience, are adopting a more cautious approach. All patients will undergo baseline brain CT before surgery and also before restarting anticoagulation postoperatively. We hope to report these findings at a later stage.

\section{CONCLUSIONS}

In this small series of patients with CTEPH post-PEA, a higher incidence of SDH was encountered. A fair proportion of the cases were asymptomatic, and this generally did not result in significant morbidity or mortality. Further research is needed to examine the mechanism of this pertinent complication, identify preventive measures, and elucidate its clinical significance. 


\section{References}

1. Jenkins DP, Biederman A, D'Armini AM, Dartevelle PG, Gan HL, Klepetko W, et al. Operability assessment in CTEPH: lessons from the CHEST-1 study. J Thorac Cardiovasc Surg. 2016;152:669-74.e3.

2. Taboada D, Pepke-Zaba J, Jenkins DP, Berman M, Treacy CM, Cannon JE, et al Outcome of pulmonary endarterectomy in symptomatic chronic thromboembolic disease. Eur Respir J. 2014;44:1635-45.

3. Fedullo PF, Auger WR, Dembitsky WP. Postoperative management of the patient undergoing pulmonary thromboendarterectomy. Semin Thorac Cardiovasc Surg. 1999;11:172-8.

4. Daily PO, Dembitsky WP, Jamieson SW. The evolution and the current state of the art of pulmonary thromboendarterectomy. Semin Thorac Cardiovasc Surg. 1999;11:152-63.

5. Mayer E, Jenkins D, Lindner J, D’Armini A, Kloek J, Meyns B, et al. Surgical management and outcome of patients with chronic thromboembolic pulmonary hypertension: results from an international prospective registry. J Thorac Cardiovasc Surg. 2011;141:702-10.

6. Jamieson SW, Kapelanski DP, Sakakibara N, Manecke GR, Thistlethwaite PA, Kerr KM, et al. Pulmonary endarterectomy: experience and lessons learned in 1,500 cases. Ann Thorac Surg. 2003;76:1457-62; discussion 1462-4.

7. Thistlethwaite PA, Kemp A, Du L, Madani MM, Jamieson SW. Outcomes of pulmonary endarterectomy for treatment of extreme thromboembolic pulmonary hypertension. J Thorac Cardiovasc Surg. 2006;131:307-13.
8. Luo WC, Huang SC, Lin YH, Lai HS, Kuo SW, Pan SC, et al. Pulmonary endarterectomy for chronic thromboembolic pulmonary hypertension-a single-center experience in Taiwan. J Formos Med Assoc. 2015;114:1197-203.

9. Ishida K, Masuda M, Tanabe N, Matsumiya G, Tatsumi K, Nakajima N. Long-term outcome after pulmonary endarterectomy for chronic thromboembolic pulmonary hypertension. J Thorac Cardiovasc Surg. 2012;144:321-6.

10. Rahnavardi M, Yan TD, Cao C, Vallely MP, Bannon PG, Wilson MK. Pulmonary thromboendarterectomy for chronic thromboembolic pulmonary hypertension: a systematic review. Ann Thorac Cardiovasc Surg. 2011;17:435-45.

11. Osada H, Marui A, Tanaka S, Meshii K, Ohnaka M, Nakajima H. Acute subdural hematoma after aortic surgery: a retrospective comparative study. Asian Cardiovasc Thorac Ann. 2015;23:24-30.

12. Krous HF, Tenckhoff L, Gould NS, Stamm SJ. Subdural hematoma following open-heart operations. Ann Thorac Surg. 1975;19:269-76.

13. Del Greco F, Krumlovsky F. Subdural haematoma in the course of haemodialysis. Lancet. 1969;2:1009-10.

14. van Asch CJ, Luitse MJ, Rinkel GJ, van der Tweel I, Algra A, Klijn CJ. Incidence, case fatality, and functional outcome of intracerebral haemorrhage over time, according to age, sex, and ethnic origin: a systematic review and meta-analysis. Lancet Neurol. 2010;9:167-76.

15. De Bonis P, Trevisi G, de Waure C, Sferrazza A, Volpe M, Pompucci A, et al Antiplatelet/anticoagulant agents and chronic subdural hematoma in the elderly. PLoS One. 2013;8:e68732. 